\title{
Synthesis of axially chiral heterobiaryl alkynes via dynamic kinetic asymmetric alkynylation $\dagger$
}

Cite this: Chem. Commun., 2016 52, 14121

Received 10th November 2016 Accepted 11th November 2016

DOI: $10.1039 / \mathrm{c} 6 \mathrm{cc} 08997 f$

www.rsc.org/chemcomm

\author{
Valentín Hornillos, ${ }^{\star a}$ Abel Ros, ${ }^{\mathrm{ab}}$ Pedro Ramírez-López, ${ }^{\mathrm{a}}$ Javier Iglesias-Sigüenza, ${ }^{\mathrm{b}}$ \\ Rosario Fernández ${ }^{\star b}$ and José M. Lassaletta*a
}

The dynamic kinetic $\mathrm{Pd}^{0}$-catalyzed alkynylation of racemic heterobiaryl sulfonates was used for the asymmetric synthesis of axially chiral heterobiaryl alkynes with a broad scope. The use of $\mathrm{Pd}(\mathrm{OAc})_{2} /$ (S)-QUINAP as the precatalyst provides products in excellent yields and enantioselectivities under mild conditions (DMSO, $40{ }^{\circ} \mathrm{C}$ ). Semireduction, 1,3-dipolar cycladdition or $\mathrm{N}$-oxidation served to illustrate the synthetic potential of the methodology.

Axially chiral biaryls are often found in natural products ${ }^{1}$ as well as biologically active molecules and constitute privileged frameworks for ligands in the field of asymmetric catalysis. ${ }^{2}$ Despite their key importance, methods to access these moieties in high efficiency and selectivity are still scarce and limited in substrate scope. ${ }^{3}$ While significant advances have been reported in asymmetric cross-couplings to build the central axis of the molecule, ${ }^{4}$ this direct strategy fails when heterocyclic coupling partners are employed. ${ }^{5}$ However, the growing number of applications of axially chiral 2-arylpyridines(isoquinolines) such as I-V (Fig. 1) in catalysis ${ }^{6}$ has stimulated the development of alternative strategies for their catalytic asymmetric synthesis. A handful of currently available methods include a kinetic resolution via $\mathrm{Pd}^{\mathrm{II}}$-catalyzed $\mathrm{C}-\mathrm{H}$ bond iodination, ${ }^{7}$ a recently reported dynamic kinetic biocatalytic reduction of configurationally labile heterobiaryl (N-oxides) aldehydes ${ }^{8}$ and two $\mathrm{C}-\mathrm{C}$ bond forming strategies: $\mathrm{Co}^{\mathrm{I}}$ or $\mathrm{Rh}^{\mathrm{I}}$-catalyzed $[2+2+2]$ cycloadditions between nitriles and alkynes (Scheme $1 \mathrm{a})^{9}$ and $\mathrm{Rh}^{\mathrm{III}}$ catalyzed $\mathrm{C}-\mathrm{H}$ functionalization of 1-aryl-benzo[ $h]$ isoquinolines (Scheme 1b). ${ }^{10}$ Additionally, our group reported in 2013, an alternative methodology consisting of a Pd-catalyzed dynamic kinetic asymmetric (DYKAT) Suzuki-Miyaura coupling between aryl boroxines and racemic heterobiaryl triflates (Scheme 1c), ${ }^{11}$ a strategy

\footnotetext{
${ }^{a}$ Instituto Investigaciones Químicas (CSIC-US), C/Américo Vespucio, 49, 41092 Sevilla, Spain. E-mail: vhornillos@iiq.csic.es, jmlassa@iiq.csic.es

${ }^{b}$ Departamento de Química Orgánica, Universidad de Sevilla,

C/Prof. García González, 1, 41012 Sevilla, Spain.E-mail: ffernan@us.es

$\dagger$ Electronic supplementary information (ESI) available: Experimental protocols, characterization data. CCDC 1506065 and 1506066. For ESI and crystallographic data in CIF or other electronic format see DOI: 10.1039/c6cc08997f
}

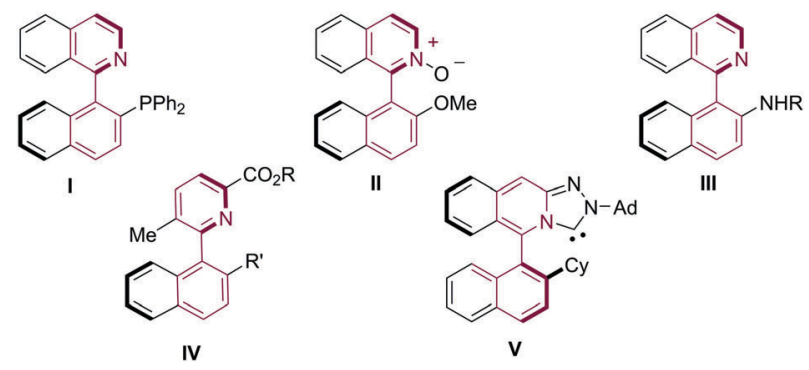

Fig. 1 Axially chiral heterobiaryls relevant to catalysis.

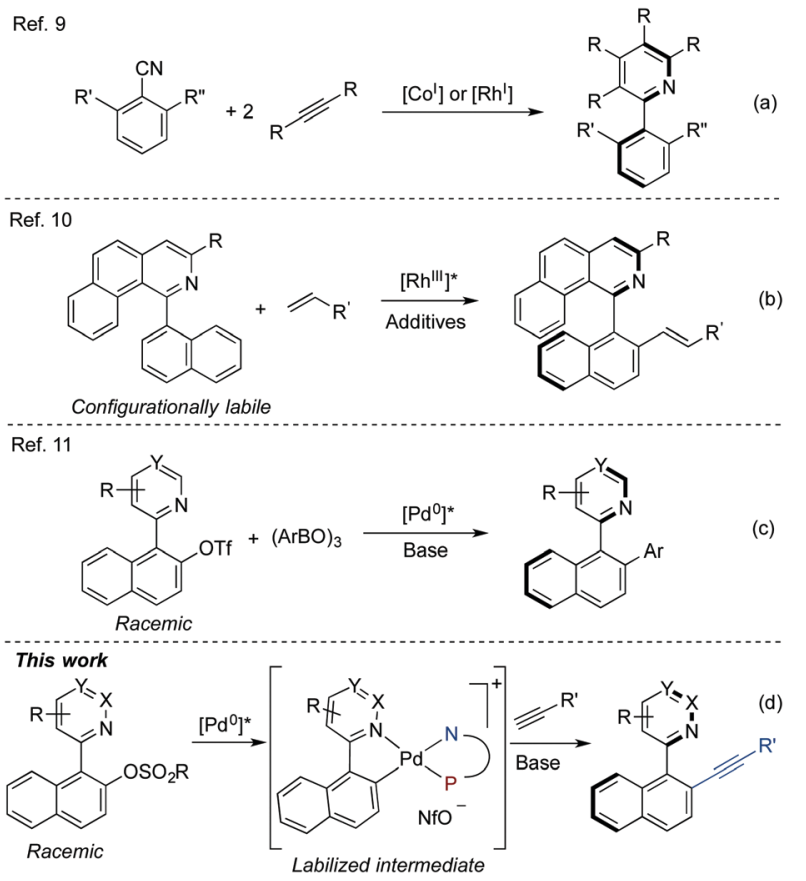

Scheme 1 C-C bond forming strategies toward axially chiral heterobiaryls.

that was later extended to perform C-P couplings for the asymmetric synthesis of heterobiaryl phosphines including QUINAP, 
PINAP, and QUINAZOLINAP analogues ${ }^{12}$ and Buchwald-Hartwig aminations leading to heterobiaryl amines (Isoquinoline-Amino Naphthalene (IAN) and analogues). ${ }^{13}$

Although the dynamic kinetic Suzuki-Miyaura coupling via DYKAT represents an appealing $\mathrm{C}-\mathrm{C}$ bond forming strategy for the atroposelective synthesis of axially chiral heterobiaryls, the absence of reactive or coordinating functionalities at the ortho position limits its further applicability (e.g., as chiral bidentate ligands or organocatalysts). ${ }^{14}$ We therefore examined the possibility of a DYKAT-based strategy for the introduction of versatile groups capable of further functionalization or coordination. Because alkynes are privileged building blocks, ${ }^{15}$ we decided to look into the asymmetric alkynylation of racemic heterobiaryl electrophiles (Scheme 1d). ${ }^{16,17}$

We selected the coupling of racemic 1-(isoquinolin-1-yl)naphthalene-2-yl nonaflate $\mathbf{1 A}$ with phenylacetylene $\mathbf{2 a}$ as a model reaction (Table 1). In the presence of $10 \mathrm{~mol} \%$ of $\mathrm{Pd}(\mathrm{dba})_{2}$ and 11 mol\% ( $R$-BINAP L1 and using DIPEA (3 eq.) as the base in dioxane at $60{ }^{\circ} \mathrm{C}$, the desired product $2 \mathrm{Aa}$ was obtained with moderate conversion and enantioselectivity (entry 1).

Table 1 Screening of reaction conditions and ligands ${ }^{a}$

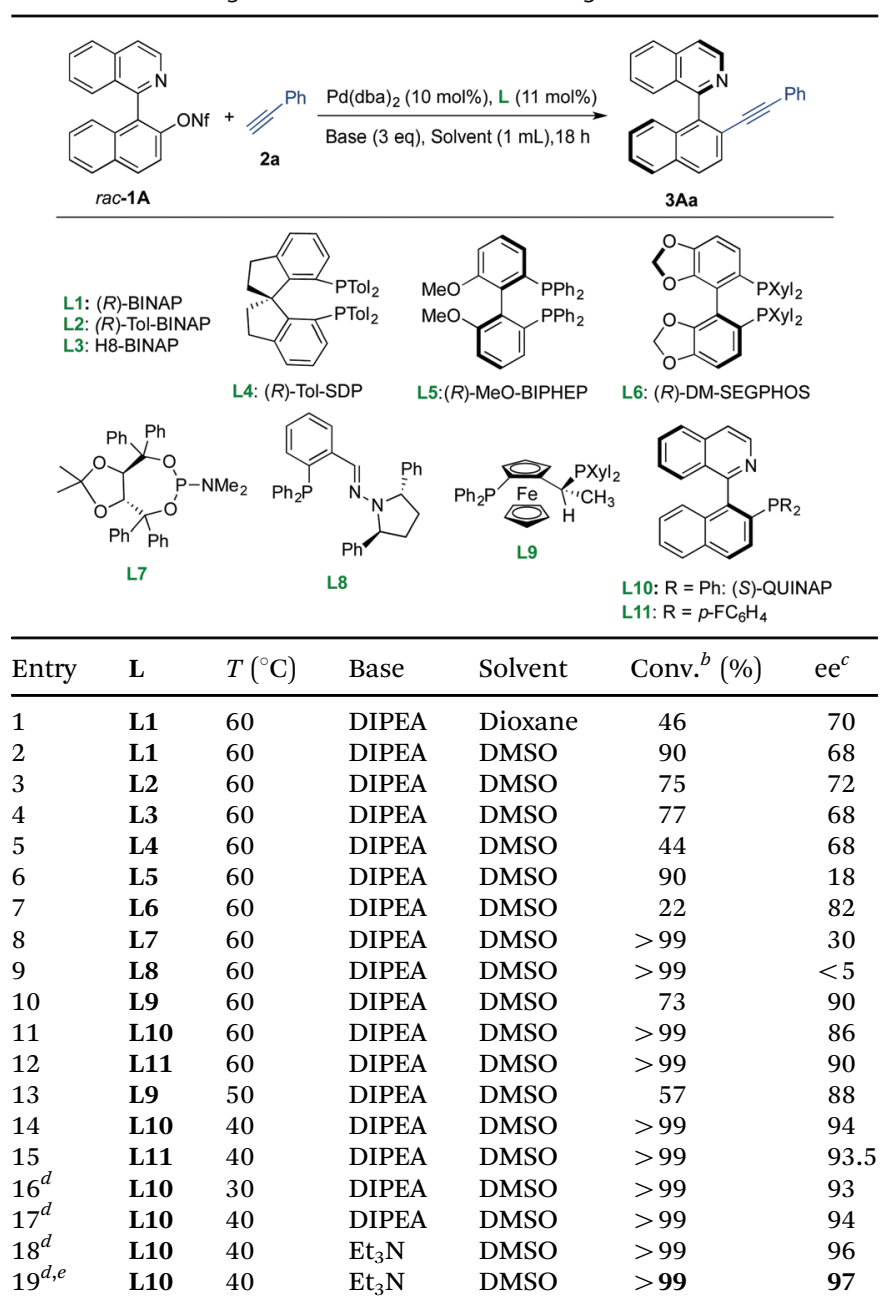

${ }^{a}$ Conditions: $0.1 \mathrm{mmol}$ of rac-1A, $0.2 \mathrm{mmol}$ of alkyne. ${ }^{b}$ Conversion by ${ }^{1} \mathrm{H}$ NMR spectroscopy. ${ }^{c}$ Determined by HPLC. ${ }^{d}[\mathrm{Pd}](5 \mathrm{~mol} \%) / \mathbf{L 1 0}$ $(6 \mathrm{~mol} \%) .{ }^{e} \mathrm{Pd}(\mathrm{OAc})_{2}$ was used instead of $\mathrm{Pd}(\mathrm{dba})_{2}$.
Although disappointing from the synthetic viewpoint, this experiment served as a proof of concept and confirmed the configurational stability of the product. A survey of different solvents revealed that DMSO facilitated high conversion while maintaining a similar enantioselectivity (entry 2). Under these conditions, different commercially available axially chiral biphosphines L2-L6 (Table 1, entries 3-7 and Table S1 in the ESI $\dagger$ ) were examined, but the enantioselectivity could not be improved. The use of phosphoramidite ligand L7 (employed in our previous dynamic kinetic Suzuki reaction) ${ }^{11}$ and phosphino-hydrazone ligand L8 (efficient in atropo-enantioselective Suzuki-Miyaura cross-couplings $)^{4 g}$ provided excellent conversions into the desired product 3Aa but with low enantioselectivities (entries 8 and 9). Finally we were pleased to find out that ligand L9, $(S)$-QUINAP L10 and the fluorinated derivative $\mathbf{L 1 1}^{12 a}$ provided higher enantioselectivities with complete conversions (entries 10-12). After an additional screening of base, Pd source and temperature (entries 13-19 and Table S1 in the ESI $\dagger$ ), we identified $\mathbf{L 1 0}$ as an optimal ligand that enables the reaction to proceed at $40{ }^{\circ} \mathrm{C}$ with a lower catalyst loading (5 mol\%) and excellent results (99\% conv., $97 \%$ ee). It is worth mentioning that no additional $\mathrm{Cu}^{\mathrm{I}}$ co-catalyst is needed in this transformation.

With the optimized reaction conditions in hand $[5 \mathrm{~mol} \%$ $\mathrm{Pd}(\mathrm{OAc})_{2} / 6 \mathrm{~mol} \%$ QUINAP, $\mathrm{Et}_{3} \mathrm{~N}$ (3 eq.) as the catalyst, DMSO, $40{ }^{\circ} \mathrm{C}$ ], we next explored the alkyne scope using $\mathbf{1 A}$ as the heterobiaryl partner (Scheme 2). Phenylacetylenes with electrondonating $\left(p-\mathrm{MeO}, p\right.$ - $\left.\mathrm{NMe}_{2}\right)$ or withdrawing substituents $(p-\mathrm{F}$, $p$-Br) afforded the desired products (3Aa-e) in excellent yields (95\% to quantitative) and enantioselectivities (up to $95 \%$ ee). Importantly, no evidence of the competing coupling at the $\mathrm{C}-\mathrm{Br}$ bond was observed in the preparation of 3Ae, highlighting how
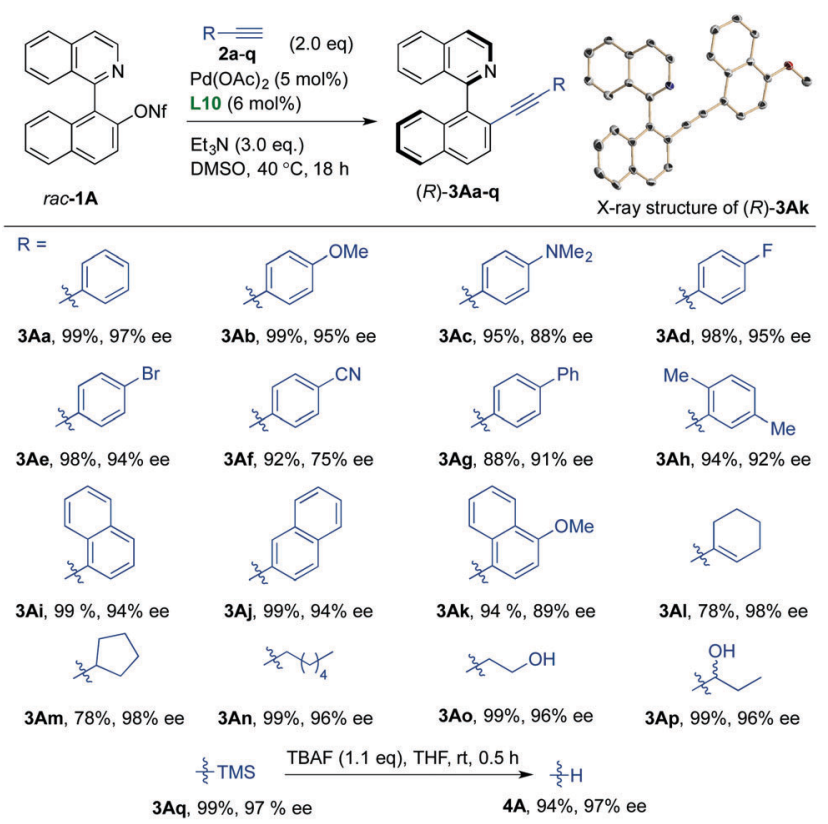

Scheme 2 Scope of alkynes. All reactions were performed at $0.1 \mathrm{mmol}$ scale and reached full conversion as determined by TLC and ${ }^{1} \mathrm{H}$ NMR spectroscopy. Isolated yields after column chromatography. Ees were determined by HPLC. 
the high chemoselectivity of the reaction allows for the inclusion of strategic functionalities prone to undergo further transformations. The lower enantioselectivity observed for 3Af can be attributed to the interferences that the coordination of the nitrile group, of either the starting alkyne 2 f or the product, might cause in the enantiodetermining step. Excellent yields and enantioselectivities were also observed for hindered aryl- or naphthylsubstituted acetylenes $\mathbf{2 h}-\mathbf{k}$, while the use of enyne $\mathbf{2 l}$ and alkynes 2m-p bearing different linear and cyclic aliphatic substituents, including a secondary propargylic and homopropargylic alcohol, also provided the desired products in excellent yields and ees. The use of trimethylsilylacetylene $\mathbf{2 q}$ led to the TMS-protected product 3Aq, also obtained in high yield and selectivity. The ensuing high-yielding deprotection with TBAF provided the terminal alkyne $\mathbf{4 A}$ without erosion of optical purity. Importantly, a lower catalyst loading $(1 \mathrm{~mol} \%$ [Pd] $/ 1.2 \mathrm{~mol} \% \mathrm{L10})$ was required for the reaction of $\mathrm{rac}-\mathbf{1 A}$ with $\mathbf{2 q}$ on a larger scale ( $2 \mathrm{mmol}, 1.1 \mathrm{~g}$ ), leading to $\mathbf{4 A}$ in $80 \%$ overall yield and with the same ee after TMS removal.

We next explored the scope of the reaction with respect to other heterobiaryl sulfonates using phenylacetylene 2a, 1-octyne 2n and trimethylsilylacetylene $\mathbf{2 q}$ as the alkyne counterparts (Scheme 3). Variations in the structure of the heterobiaryl frame did not have an impact on the reaction outcome. Thus, quinazoline and phthalazine derivatives $\mathbf{1 B}$ and $\mathbf{1 C}$ afforded the corresponding alkynes with excellent selectivities, independently of the leaving
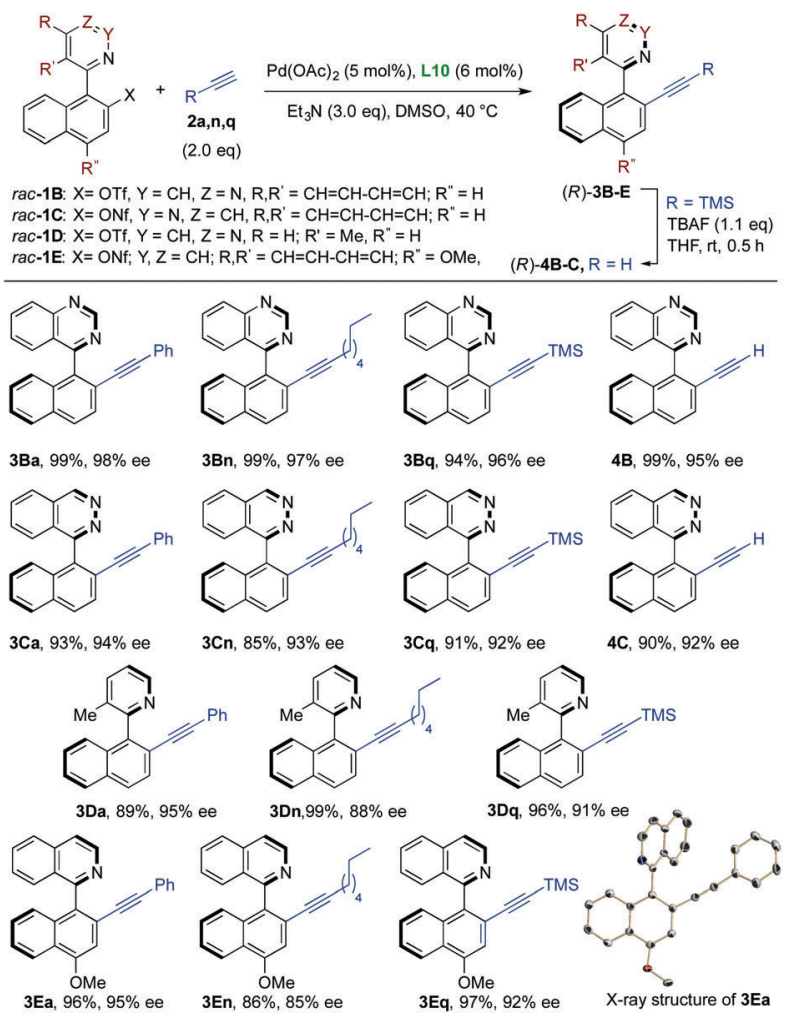

Scheme 3 Scope of heterobiaryls. All reactions were performed at $0.1 \mathrm{mmol}$ scale and reached full conversion as determined by TLC and ${ }^{1} \mathrm{H}$ NMR spectroscopy. Isolated yields after column chromatography. Ees were determined by HPLC.

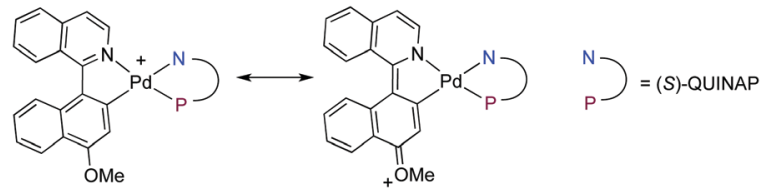

Fig. 2 Oxidative addition intermediate from 1E.

group used (OTf or ONf). As mentioned before, the corresponding TMS-protected alkynes could be desilylated using TBAF to afford the terminal alkynes $\mathbf{4 B}$ and $\mathbf{4 C}$ in high yield without compromising the configurational integrity of the final product. Additionally, heterobiaryl alkynes derived from picoline 1D could also be obtained in high yields and ees. Heterobiaryl nonaflate 1E is a priori a more challenging substrate for the undesired effects of the push-pull conjugation with the OMe group in the key oxidative addition intermediate: first, a partial double bond character and a shorter $\mathrm{C}(1)-\mathrm{C}\left(1^{\prime}\right)$ bond length are expected to slow down the required atropoisomerization at this stage $^{18}$ (Fig. 2). Second, the dissociation of the N-Pd bond, enabling the coordination of the alkyne, is also made difficult by the higher basicity of the isoquinoline $\mathrm{N}$ atom. In fact, $\mathbf{1 E}$ was not a suitable substrate in previous DYKAT-based strategies, ${ }^{10,12 a, 13}$ but the better efficiency of the alkynylation reaction allowed the isolation of compounds 3Ea,n,q in excellent yields and good to excellent ees. The absolute $R$ configurations of $(R)$-3Ak and $(R)$-3Ea were determined by X-ray diffraction analysis while those of other products 3 were assigned by analogy.

To further demonstrate the potential of this new methodology, the terminal alkyne $\mathbf{4 A}$ was used as a platform for the synthesis of new families of axially chiral heterobiaryls that are otherwise difficult to obtain. Highly chemoselective semireduction of the alkyne was accomplished in good yield according to a recently reported procedure ${ }^{19}$ (Scheme 4a). The resulting compound 5 represents a novel example (with axially chirality) of the so far underdeveloped chiral N/olefin hybrid ligands (e.g., OlefOx) that have already shown an excellent performance in asymmetric catalysis. $^{20}$ Furthermore, a unique axially chiral $N, N$-ligand 6 was prepared via $\mathrm{Cu}(\mathrm{I})$-catalyzed dipolar cycloaddition ${ }^{21}$ of $\mathbf{4 A}$ with benzyl azide in good yield under mild conditions (Scheme 4b). Finally, selective N-oxidation of $\mathbf{4 A}$ using $m$-CPBA afforded $\mathrm{N}$-oxide 7 in 94\% yield (Scheme 4c). Remarkably, the stereochemical integrity is completely preserved for all the above transformations.

In summary, we have developed a highly efficient methodology for the synthesis of heterobiaryl alkynes based on a dynamic kinetic asymmetric alkynylation reaction. Broad scope, functional group

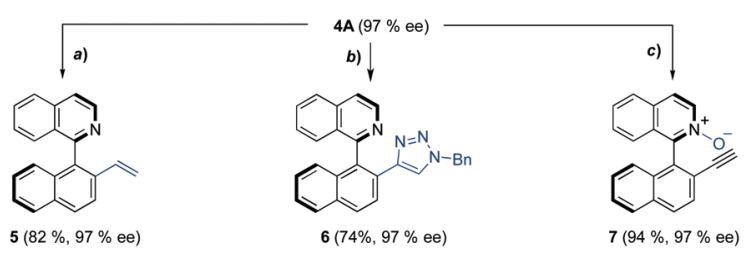

Scheme 4 Representative derivatizations. (a) IPrCuOtBu (5 mol\%), PMHS (1.2 eq.), toluene, rt, $14 \mathrm{~h}$; (b) $\mathrm{BnN}_{3}$ (1.5 eq.) $\mathrm{CuSO}_{4}$ (10 mol\%), sodium ascorbate (20 mol\%), $\mathrm{tBuOH} / \mathrm{H}_{2} \mathrm{O}, 35^{\circ} \mathrm{C}, 5 \mathrm{~h}$; (c) $\mathrm{m}$-CPBA (2 eq.), THF, rt, $3 \mathrm{~h}$. 
tolerance and excellent enantioselectivities were achieved using a $\mathrm{Pd}^{0} / \mathrm{QUINAP}$ catalytic system (down to $1 \mathrm{~mol} \%$ ) under mild conditions $\left(40{ }^{\circ} \mathrm{C}\right)$. The newly installed alkynyl group was readily transformed to access novel axially chiral bidentate ligands.

We thank the Spanish MINECO (Grants CTQ2013-48164-C2-1-P and CTQ2013-48164-C2-2-P, contract RYC-2013-12585 for A.R.), European FEDER Funds, and Junta de Andalucía (Grant 2012/ FQM 10787) for financial support. VH thanks the EU 7th Framework Program, Marie Skłodowska-Curie actions for a Talent Hub fellowship (COFUND - Grant no. 291780).

\section{Notes and references}

1 (a) G. Bringmann, T. Gulder, T. A. M. Gulder and M. Breuning, Chem. Rev., 2011, 111, 563-639; (b) M. C. Kozlowski, B. J. Morgan and E. C. Linton, Chem. Soc. Rev., 2009, 38, 3193-3207.

2 For reviews, see: (a) R. Noyori and H. Takaya, Acc. Chem. Res., 1990, 23, 345-350; (b) Y. Chen, S. Yekta and A. K. Yudin, Chem. Rev., 2003, 103, 3155-3212; (c) H. Shimizu, I. Nagasaki and T. Saito, Tetrahedron, 2005, 61, 5405-5432; (d) T. Akiyama, J. Itoh and K. Fuchibe, Adv. Synth. Catal., 2006, 348, 999-1010; (e) Y.-M. Li, F.-Y. Kwong, W.-Y. Yu and A. S. C. Chan, Coord. Chem. Rev., 2007, 251, 2119-2144; $(f)$ T. Akiyama, Chem. Rev., 2007, 107, 5744-5758; $(g)$ Y. Canac and R. Chauvin, Eur. J. Inorg. Chem., 2010, 2325-2335; (h) D. Parmar, E. Sugiono, S. Raja and M. Rueping, Chem. Rev., 2014, 114, 9047-9153.

3 (a) G. Bringmann, A. J. Price Mortimer, P. A. Keller, M. J. Gresser, J. Garner and M. Breuning, Angew. Chem., Int. Ed., 2005, 44, 5384-5427; (b) G. Ma and M. P. Sibi, Chem. - Eur. J., 2015, 21, 11644-11657; (c) J. Wencel-Delord, A. Panossian, F. R. Leroux and F. Colobert, Chem. Soc. Rev., 2015, 44, 3418-3430.

4 Seminal work and recent examples: (a) T. Hayashi, S. Niizuma, T. Kamikawa, N. Suzuki and Y. Uozumi, J. Am. Chem. Soc., 1995, 117, 9101-9102; (b) J. Yin and S. L. Buchwald, J. Am. Chem. Soc., 2000, 122, 12051-12052; (c) T. Shimada, Y.-H. Cho and T. Hayashi, J. Am. Chem. Soc., 2002, 124, 13396-13397; (d) K. Sawai, R. Tatumi, T. Nakahodo and H. Fujihara, Angew. Chem., Int. Ed., 2008, 47, 6917-6919; (e) A. Bermejo, A. Ros, R. Fernández and J. M. Lassaletta, J. Am. Chem. Soc., 2008, 130, 15798-15799; $(f)$ T. Yamamoto, Y. Akai, Y. Nagata and M. Suginome, Angew. Chem., Int. Ed., 2011, 50, 8844-8847; ( $g$ ) A. Ros, B. Estepa, A. Bermejo, E. Álvarez, R. Fernández and J. M. Lassaletta, J. Org. Chem., 2012, 77, 4740-4750; (h) Y. Zhou, S. Wang, W. Wu, Q. Li, Y. He, Y. Zhuang, L. Li, J. Pang, Z. Zhou and L. Qiu, Org. Lett., 2013, 15, 5508-5511; (i) G. Xu, W. Fu, G. Liu, C. H. Senanayake and W. Tang, J. Am. Chem. Soc., 2014, 136, 570-573. Recent reviews: $(j)$ Y. Uozumi, Comprehensive Chirality, Elsevier, 2012, vol. 4, ch. 4.3; (k) D. Zhang and Q. Wang, Coord. Chem. Rev., 2015, 286, 1-16.

5 For exceptions reaching moderate enantioselectivities see: (a) A. Mosquera, M. A. Pena, J. Pérez Sestelo and L. A. Sarandeses, Eur. J. Org. Chem., 2013, 2555-2562; (b) K. Yamaguchi, J. Yamaguchi, A. Studer and K. Itami, Chem. Sci., 2012, 3, 2165-2169; (c) K. Yamaguchi, H. Kondo, J. Yamaguchi and K. Itami, Chem. Sci., 2013, 4, 3753-3757.

6 QUINAP and analogues: (a) E. Fernández, P. J. Guiry, K. P. T. Connole and J. M. Brown, J. Org. Chem., 2014, 79, 5391-5400, and references cited therein; Axially chiral pyridine (isoquinoline) N-oxides: (b) A. V. Malkov, P. Ramírez-López, L. Biedermannová, L. Rulíšek, L. Dufková, M. Kotora, F. Zhu and P. Kočovský, J. Am. Chem. Soc., 2008, 130, 5341-5348; Isoquinoline-Amino Naphthalene (IAN): (c) S. B. Cortright and J. N. Johnston, Angew. Chem., Int. Ed., 2002, 41, 345-348; Axially quiral 5-methyl-(1-naphthyl)picolinic acids(esters): (d) S. Tanaka, T. Seki and M. Kitamura, Angew. Chem., Int. Ed., 2009, 48, 8948-8951; Axially chiral N-heterocyclic carbenes: (e) J. Francos, F. Grande-Carmona, H. Faustino, J. Iglesias-Sigüenza, E. Díez, I. Alonso, R. Fernández, J. M. Lassaletta, F. López and J. L. Mascareñas, J. Am. Chem. Soc., 2012, 134, 14322-14325; Axially chiral pyridoxamines: $(f)$ Y. E. Liu, Z. Lu, B. Li, J. Tian, F. Liu, J. Zhao, C. Hou, Y. Li, L. Niu and B. Zhao, J. Am. Chem. Soc., 2016, 138, 10730-10733.

7 D.-W. Gao, Q. Gu and S.-L. You, ACS Catal., 2014, 4, 2741-2745.

8 S. Staniland, R. W. Adams, J. J. W. McDouall, I. Maffucci, A. Contini, D. M. Grainger, N. J. Turner and J. Clayden, Angew. Chem., Int. Ed., 2016, 55, 10755-10759.

9 Seminal work: (a) A. Gutnov, B. Heller, C. Fischer, H. J. Drexler, A. Spannenberg, B. Sundermann and C. Sundermann, Angew. Chem., Int. Ed., 2004, 43, 3795-3797; (b) Review: K. Tanaka, Chem. - Asian J., 2009, 4, 508-518; Recent examples: M. Hapke, K. Kral, C. Fischer, A. Spannenberg, A. Gutnov, D. Redkin and B. Heller, J. Org. Chem., 2010, 75, 3993-4003; (c) N. Sakiyama, D. Hojo, K. Noguchi and K. Tanaka, Chem. - Eur. J., 2011, 17, 1428-1432.

10 (a) J. Zheng and S.-L. You, Angew. Chem., Int. Ed., 2014, 53, 13244-13247; (b) J. Zheng, W.-J. Cui, C. Zheng and S.-L. You, J. Am. Chem. Soc., 2016, 138, 5242-5245.

11 A. Ros, B. Estepa, P. Ramírez-López, E. Álvarez, R. Fernández and J. M. Lassaletta, J. Am. Chem. Soc., 2013, 135, 15730-15733.

12 (a) P. Ramírez-López, A. Ros, B. Estepa, R. Fernández, B. Fiser, E. Gómez-Bengoa and J. M. Lassaletta, ACS Catal., 2016, 6, 3955-3964; (b) See also: V. Bhat, S. Wang, B. M. Stoltz and S. C. Virgil, J. Am. Chem. Soc., 2013, 135, 16829-16832.

13 P. Ramírez-López, A. Ros, A. Romero-Arenas, J. Iglesias-Sigüenza, R. Fernández and J. M. Lassaletta, J. Am. Chem. Soc., 2016, 138, 12053-12056.

14 (a) T. P. Yoon and E. N. Jacobsen, Science, 2003, 299, 1691-1693; (b) Privileged Chiral Ligands and Catalysts, ed. Q.-L. Zhou, Wiley-VCH, Weinheim, 2011, ch. 4, p. 137.

15 (a) R. Chinchilla and C. Nájera, Chem. Rev., 2014, 114, 1783-1826; (b) F. Xie, Z. Qi, S. Yu and X. Li, J. Am. Chem. Soc., 2014, 136, 4780-4787, and references cited therein.

16 Reviews: (a) R. Chinchilla and C. Nájera, Chem. Rev., 2007, 107, 874-922; (b) R. Chinchilla and C. Nájera, Chem. Soc. Rev., 2011, 40, 5084-5121; (c) J. Magano and J.-R. Dunetz, Chem. Rev., 2011, 111, 2177-2250; (d) M. Schilz and H. Plenio, J. Org. Chem., 2012, 77, 2798-2807.

17 For asymmetric Sonogashira couplings in other contexts see: (a) K. Kanda, T. Koike, K. Endo and T. Shibata, Chem. Commun., 2009, 1870-1872; (b) H. Zhou and Y. Uozumi, Synlett, 2013, 2550-2554.

18 M. Gómez-Gallego, M. Martín-Ortiz and M. A. Sierra, Eur. J. Org. Chem., 2011, 6502-6506.

19 (a) A. M. Whittaker and G. Lalic, Org. Lett., 2013, 15, 1112-1115; (b) See also: K. Semba, T. Fujihara, T. Xu, J. Terao and Y. Tsuji, Adv. Synth. Catal., 2012, 354, 1542-1550.

20 B. T. Hahn, F. Tewes, R. Fröhlich and F. Glorius, Angew. Chem., Int. Ed., 2010, 122, 1143-1146.

21 M. Meldal and C. W. Tornøe, Chem. Rev., 2008, 108, 2952-3015. 